\title{
The Development of Suicides in the Scandinavian and the Post-Soviet Baltic Countries in a Postindustrial-Country Context
}

\section{FAUSTAS STEPUKONIS}

Senior Assistant

Department of Social Sciences

Klaipeda University

Klaipeda, Lithuania

\begin{abstract}
A review of developmental trends in the suicide rate in the Baltic region and the OECD countries from the 1960s until the present is the focus of this article. The developmental trends are grouped into three typical clusters: the first cluster, distinguished by the highest suicide rates, comprises the former Soviet countries of Estonia, Latvia, Lithuania, and Russia; the second, the Scandinavian countries as an OECD subgroup with relatively high suicide rates in regard to the OECD average; and the third the postindustrial OECD countries as a whole, distinguished by a lower suicide level than in the previous clusters, but significantly exceeding the "third" world average.

It is argued that the post-Soviet Baltic and Scandinavian model of suicide development can be explained by Durkheim's classical suicide theory. However, explaining the postindustrial type of suicide tendencies requires acceptance of a long-lasting anomie model for the prediction of suicide rates. The discussion of long-lasting anomie features and their relation to the suicide rate is presented.

The conclusion is that there are preconditions and empirical evidence for predicting the process of a declining suicide rate in the groups of the countries investigated.
\end{abstract}

Keywords: suicides, Durkheim, anomie, social pathology, Scandinavia, Baltic Sea Area, Baltic States, postindustrial society, $\mathrm{OECD}$

\section{Introduction}

A hundred years ago, in 1897, the French sociologist and philosopher Emile Durkheim published Le suicide. His ideas explaining the mechanism of suicide dynamics in different societies appear to be viable to this day. Despite the sometimes severe critics of Durkheim's explanations for suicide, his theory still remains a classical theory and is widely used.

The centenary of Durkheim's theory provides an occasion for rethinking his ideas and for searching for explanations for the phenomenon of suicide in the societies of today. However, it is not only the anniversary of the well-known theory that prompts an analysis of suicide tendencies, but also the fact that these tendencies, unfortunately, are chronically unfavorable in the Scandinavian countries and extremely threatening in the post-Soviet Baltic countries. In addition, the Baltic Sea area populations - Sweden, Finland, the area of St. Petersburg, Ingria, Estonia, Latvia, and Lithuania - are the focus of the 1997 volume of the Yearbook of Population Research in Finland.

All these reasons, in corpore, gave impetus to the study of at least two problems. The first 
problem can be formulated as follows: to what extent can the suicide anomalies of the Baltic sea area populations be explained by Durkheim's classical theory? The second is what future tendencies can be expected in the development of suicide if Durkheim's theory still is applicable?

\section{Review of the theory and data}

According to Durkheim (1897), the phenomenon of suicide is not only an individual action, belonging to the sphere of psychology, but also a societal characteristic. An analysis of suicide rate statistics in 19th-century societies drove Durkheim to the conclusion that "at each moment of its history, therefore, each society has a definite aptitude for suicide $(1989,48)$." The variation of suicide rates in different societies was explained by Durkheim with the society's degree of social integration and regulation: a lack of integration causes an increase in "egoistic" suicides and a lack of regulation causes an increase in "anomic" suicides. On the other hand, too much integration causes an increase in "altruistic" suicides and too much regulation an increase in "fatal" suicides. Thus, according to Durkheim, social integration (family, societal ties) and regulation (norms, traditions) should not be too rigorous or too soft in order not to become generators of suicide.

In the context of Durkheim's theory, the populations under investigation in this article are clustered into three groups. The first group - the post-Soviet Baltic countries - is composed of Estonia, Latvia, Lithuania, and Russia. Russia was included instead of St. Petersburg and Ingria, due to the unavailability of data on suicides in St. Petersburg and Ingria (there is no reason to presume essentially different suicide tendencies for the populations of St. Petersburg and Ingria as compared to Russia). The second group - the Scandinavian countries as an OECD subgroup - is made up of Denmark, Norway, Finland, and Sweden. Iceland was not included in this group because its suicide rates are calculated on a statistically insufficient number of cases of suicide. The third group - all of the OECD countries - includes 22 of the 24 postindustrial OECD economies as of 1973: Australia, Austria, Belgium, Canada, Denmark, Finland, France, Germany, Greece, Ireland, Italy, Japan, Luxembourg, the Netherlands, New Zealand, Norway, Portugal, Spain, Sweden, Switzerland, the United Kingdom, and the USA. Iceland is not included in this group for the above-mentioned reason, and Turkey because of the absence of suicide-rate data. Data on the suicide rates for the period 1960 to 1996 was obtained from the UN Demographic Yearbook annals and other sources (see Appendices 1 and 2). Statistical analysis of data was conducted using the SPSS version 4.0 program.

It should be stressed that not only geographical or economic factors determined the groupings of countries. The main factor in classifying countries into three clusters was the typical suicide tendencies of the countries constituting each cluster (see Figure 1, Appendix 1).

The Scandinavian model of suicide development is similar to the model of all the OECD countries. However, the mean (unweighted average) of the suicide rates in the Scandinavian countries was higher, from $27.1 \%$ (in 1961) to $49.5 \%$ (in 1980) during the entire period investigated - from 1960 to 1993. Taken separately, the Scandinavian countries - Denmark, Finland, and Sweden exceeded the average level of suicides for the OECD countries during the entire period investigated, and only Norway lagged behind the OECD average until the late 1980s. However, in the last years Norway has also lost its favorable position in the suicide statistics.

Both models of suicide tendencies - the Scandinavian and the OECD model - are similar in their gradual increase of suicide rates from the beginning of the investigated period until approximately the mid-1980s and in a decrease in recent years. The tendency to have a relatively moderate increase in the suicide rate until the mid-1980s is common for most OECD countries, including Scandinavia; only Japan and the UK show a slight decrease in suicide rates in the 1980 s as compared to 1960 . It can be concluded that the Scandinavian countries (as an OECD subgroup) and the OECD countries as a whole represent two types of suicide development, which are similar in character (first a moderate increase, then a decrease), but different in the level of suicide rates (Scandinavian is distinguished by a higher level). 
Figure 1. Suicide development in the OECD countries, in Scandinavia and in Lithuania, 19601996.

Suicide rates per 100,000 pepulation

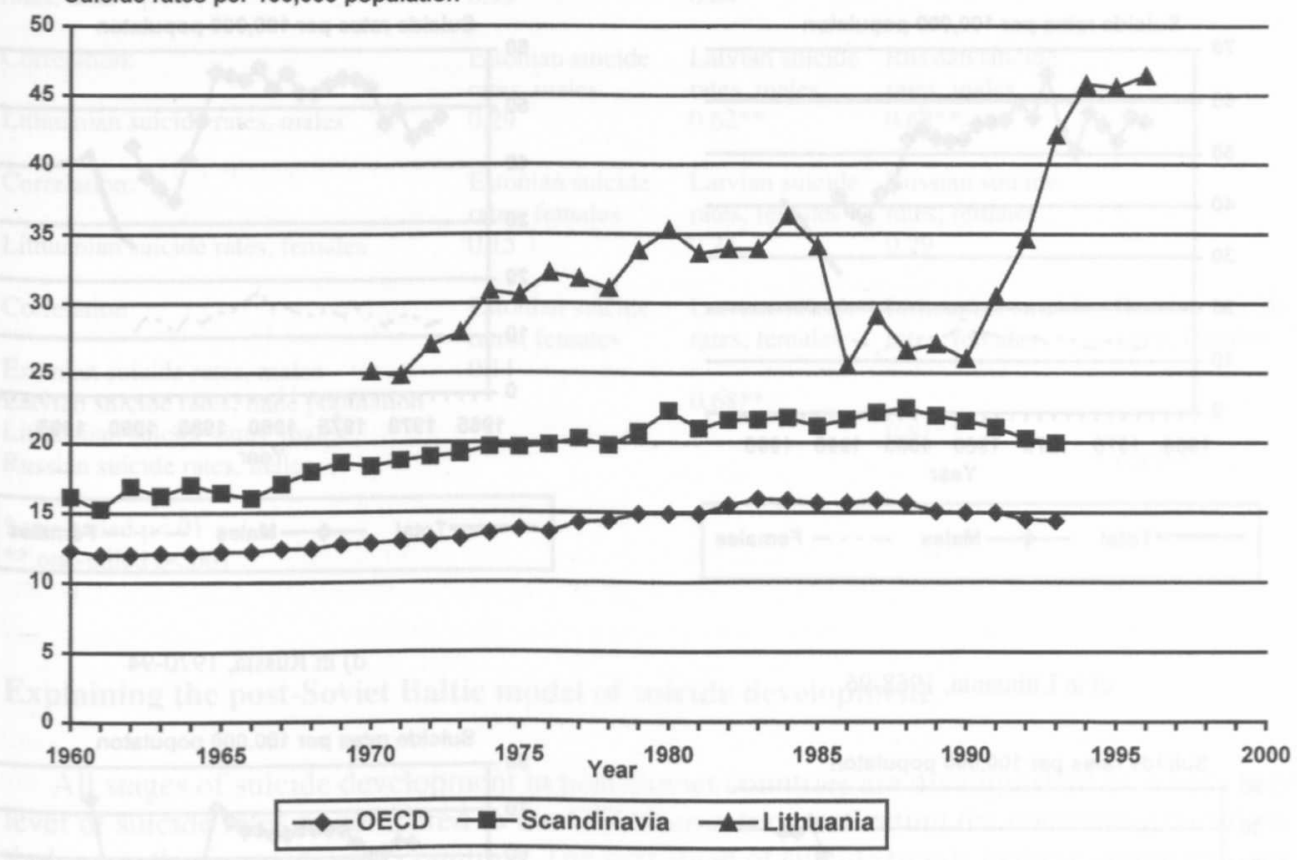

Source: see Appendices 1,2

The former Soviet Baltic countries, including Russia, show an essentially different type of suicide development (see Figure 2). This development consists of at least three stages: first stagnation or a moderate increase in the suicide rate from the beginning of the investigated period until 1984, second - a sharp decline from 1984 to approximately 1987 , and third - a sharp increase starting in the late $1980 \mathrm{~s}$. These tendencies are common for the populations of the four countries investigated, and especially evident for the male population. Fragmentary data of suicide rates for the total populations of Estonia, Latvia, and Russia (see Appendix 2) does not allow comparison of their tendencies in Figure 1. However, it seems that comprehensive data for the total population of Lithuania represents the typical dynamics of suicide development for all four countries, for both male and female populations. This proposal is supported by statistically significant correlations or at least positive tendencies toward significant correlation between the Lithuanian suicide rates for the total population and the male and female population, between the Lithuanian suicide rates for males and females and the Estonian, Latvian, and Russian males and females and between the Estonian, Latvian, Lithuanian and Russian suicide rates for the male population and the respective female population (see Table 1). It can be concluded that the Lithuanian serpent-like development of suicides for the total population, shown in bold in Figure 2c, represents typical suicide tendencies for populations of the former Soviet Baltic countries and Russia. 
Figure 2a-d. Development of suicide in post-Soviet countries.

a) in Estonia, 1968-94

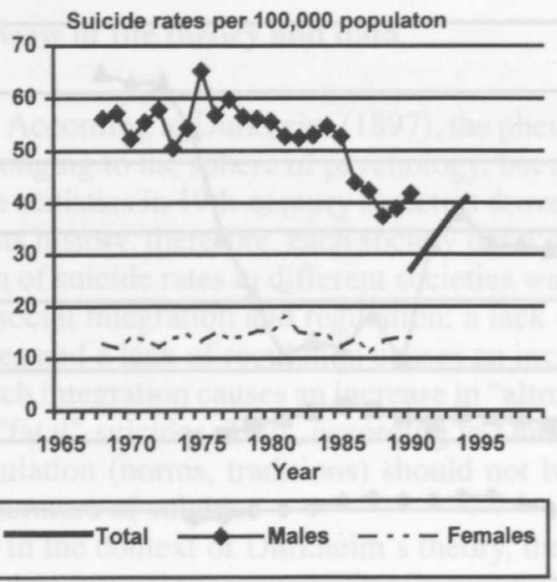

c) in Lithuania, 1968-96

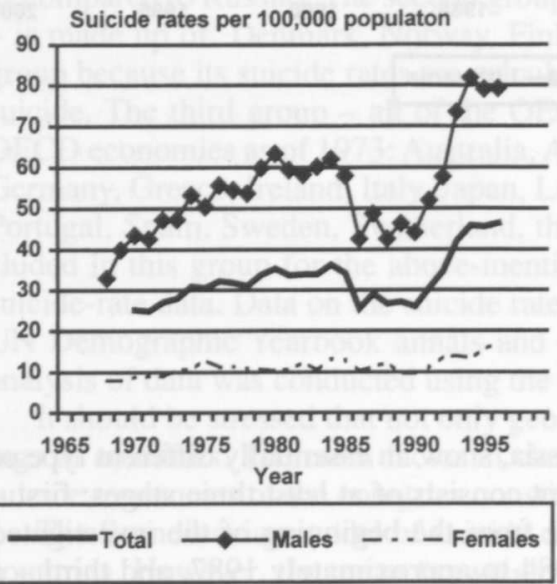

b) in Latvia, 1968-96

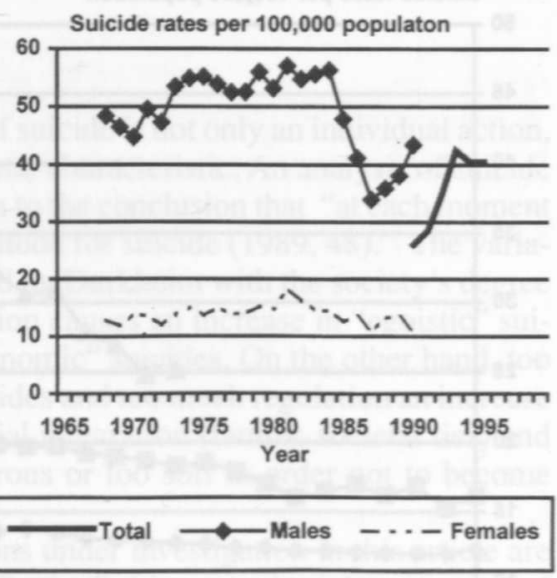

d) in Russia, 1970-94

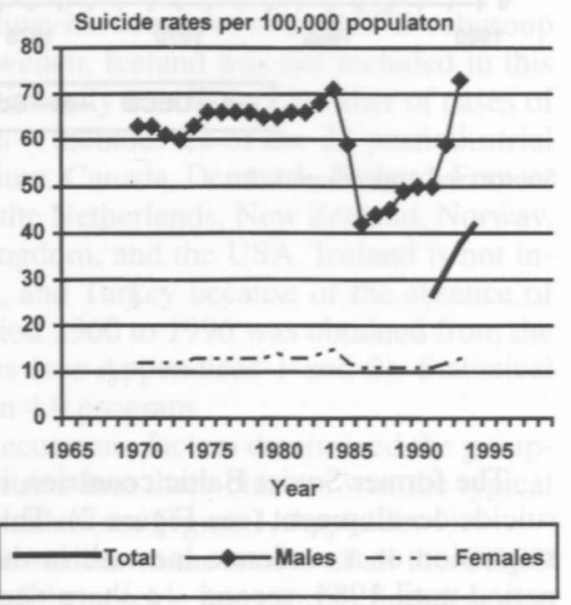

Source: see Appendix 2 
Table 1. Correlation analysis results for Estonia, Latvia, Lithuania, and Russia.

Correlation:
Lithuanian suicide
rates, total
Correlation:
Lithuanian suicide rates, males
Correlation:
Lithuanian suicide rates, females
Correlation:
Estonian suicide rates, males
Latvian suicide rates, male population
Lithuanian suicide rates, males
Russian suicide rates, males
* one-tailed $\mathrm{p}<.01$
** one-tailed $\mathrm{p}<.001$

Lithuanian suicide Lithuanian suicide rates, males rates, females

$0.99 * * * .84 * *$

Estonian suicide Latvian suicide Russian suicide rates, males rates, males rates, males 0.29 $0.62 * *$ $0.68^{* *}$

Estonian suicide Latvian suicide Russian suicide rates, females rates, females rates, females 0.15 0.27 0.29

Estonian suicide 0.11

Latvian suicide

Lithuanian suicide

Russian suicide rates, females rates, females rates, females

$0.68 * *$ $0.81^{\text {*** } *}$ $0.87^{* *}$

\section{Explaining the post-Soviet Baltic model of suicide development}

All stages of suicide development in post-Soviet countries are distinguished by a very high level of suicide rates as compared to the OECD countries, reflecting the continuing social pathology in the former Soviet countries. The first stage of suicide trends in these countries coincides with the period of stagnation in the former Soviet Union. The characteristic feature of the stagnation period was totalitarian and dogmatic regulation of the political, ideological, economical, and cultural life of Soviet societies by the governing nomenclature. This resulted, according to Okolski (1991), in a "syndrome of withdrawal" which gradually emerged among people in Eastern Europe, with growing disillusionment in the "real socialism". In Durkheim's terms, the Soviet stagnation period can be described as a period of too much regulation of societies, stimulating an increase in suicides.

The second stage in the development of suicides in the former Soviet countries coincides with the years of drastic antialcohol campaign, perestroika, and glasnost. According to Värnik, Wasserman, and Eklund (1994), "Analysis of male suicides during perestroika in the former USSR has revealed the close connection between the sharp decline in suicides in the first few years of the period and the nationwide restrictive alcohol policy simultaneously pursued." According to the same authors, "Another factor hypothetically working against suicide may have been 'spiritual liberation', with swelling hopes of a democratic order to come.” In Durkheim's terminology "spiritual liberation" would mean, possibly, moving away from "too much regulation", and, consequently, a decrease in suicides. It seems that a decrease in suicides due to perestroika and glasnost would support Durkheim's theory.

The third stage - a sharp increase in suicides starting at the end of the $1980 \mathrm{~s}$ - is undoubtedly connected with anomie development in post-Soviet societies. Anomie developed as a result of large-scale political, economic, and social reforms during the transition to market economies. According to Durkheim, fast changes in living conditions stimulate alienation, social disintegration, temporal deterioration of morality, and a spread of criminality and other social pathology, including an increase in suicides. The evidence shows that the above-mentioned features are characteristic of the post-Soviet region countries. For example, according to the latest data (UN 1997, 487-508; Statistikos departamentas 1997, 142), homicide rates for Estonia in 1996, Latvia in 1995, Lithuania in 1996, and Russia in 1994 were 19.9, 18.0, 9.3, and 32.4 respectively, when for the Scandinavian countries this rate constituted 2.6 on average, and 
for 20 out of 22 OECD countries - only 2.1 per 100,000 persons.

Not only increasing anomie, but also worsening social integration explains negative tendencies in suicide in post-Soviet countries. One of the basic features of societal integration - family ties - suffered erosion during the last decades, at least in Lithuania (see Table 2). It is believed that marriage and having children integrate people, while divorce disintegrates them. According to the latest data these characteristics are not favorable for post-Soviet Baltic countries as compared to the Scandinavian and the OECD countries, see Table 3. On the other hand they do not differ significantly and cannot explain the large differences in suicide rates by their own.

Table 2. Development in marriage, divorce and live births in Lithuania, 1961-1996.

$\begin{array}{lccr}\text { Year } & \begin{array}{c}\text { Marriages per 1,000 } \\ \text { population }\end{array} & \begin{array}{l}\text { Diverces per } 1,000 \\ \text { population }\end{array} & \begin{array}{l}\text { Live births per } \\ 1,000 \text { population }\end{array} \\ 1961-65 & 9.0 & 0.9 & 19.9 \\ 1966-70 & 9.4 & 2.0 & 17.2 \\ 1971-75 & 8.9 & 2.4 & 14.8 \\ 1976-80 & 9.2 & 3.1 & 13.6 \\ 1981-85 & 9.5 & 3.2 & 14.8 \\ 1986-90 & 9.7 & 3.3 & 16.3 \\ 1991-95 & 7.2 & 3.4 & 14.1 \\ 1996 & 5.5 & 3.0 & 12.1\end{array}$

Source: Statistikos departamentas 1997, 18, 20, 21.

Thus, the Baltic model of suicide development for former Soviet societies can be explained on the basis of Durkheim's social regulation theory. The first stage was possibly determined by too much regulation, the second by moderate regulation, and the third by lack of regulation.

\section{Explaining the Scandinavian model of suicide development}

Lester (1994) has analyzed the Scandinavian variation of suicide over the period of 19501985 in the context of Durkheim's theory. On the basis of time series regression results which reflect the association of suicides with such societal characteristics as marriage, divorce, and children, he concluded that despite the fact that "not every prediction from Durkheim's theory of suicide is confirmed. [...] [the] theory is still of use today in predicting national time series suicide rates."

It seems that the classical theory predicts not only suicide rates in individual Scandinavian countries, but also explains why the Scandinavian region as a whole tends to have higher suicide rates than the OECD average. It is known that Scandinavian countries are traditionally distinguished by unfavorable statistics concerning some of the basic societal integration characteristics such as the marriage and divorce rate (see Table 3), as well as live births outside marriage, the percentage of one-person households, and the spread of criminality.

The suicide phenomenon is the most visible peak of the social disintegration iceberg, which consists of less visible or almost invisible components, such as weak social ties, criminality, fatal accidents, hidden alcoholism, drug abuse, depression, etc. It should be concluded that measured by suicide rate in the context of Durkheim's theory, Scandinavian societies are less integrated on average than the OECD countries as a whole.

The halt of the centuries-long increase in suicides in the Scandinavian countries and in the OECD countries as a whole in the mid-1980s prompts a hypothesis of a historical stabilization of negative tendencies in the spheres of the social disintegration process of advanced societies. However, in order to avoid ungrounded speculation based on the analysis of a few Scandinavian countries, it is more expedient to analyze these tendencies for a greater number of OECD countries. Such an analysis is presented in the next section. 
Table 3. Marriage, divorce, and live births in post-Soviet Baltic, Scandinavian, and OECD countries according to the latest data

Marriages per 1,000 population (year)

Post-Soviet Baltic coutries

Scandinavian countries

OECD countries

$5.6(1995)$
$4.9(1994-95)$
$5.6(1993-95)$

$5.6(1995)$
$4.9(1994-95)$
$5.6(1993-95)$
Divorces per 1,000 population (year)

$3.2(1995)$

$2.5(1994-95)$

$2.2^{1}(1993-95)$
Live births per 1,000 population (year)

$9.5(1995)$

$12.8(1995)$

$12.1(1994-95)$

Source: Statistikos departamentas 1997, 134-37; UN 1997, 142-49.

${ }^{1}$ Ireland not included.

Note: The averages for regions are unweighted arithmetic means of the countries in the group.

\section{Discussion of the OECD model of suicide development}

The OECD societies, including Scandinavia, represent the most developed countries of the world. They are distinguished by the highest economic, cultural, and quality of life indicators. These market economy countries have developed wide-spread welfare nets for their societies, put into practice effective policies protecting human rights and public health and realized countless measures for improving human life. However, measured by the incidence of suicide, OECD societies suffer a relatively high level of social pathology compared to the "third" world countries. The average suicide level for OECD countries in 1993 was 14.3 per 100,000 population (see Appendix 1), when for non-OECD African, American, and Asian countries this average was only 7.5 (according to the latest statistically reliable data for 36 countries, UN 1997, 486508).

The suicide statistics and certain other negative societal characteristics spoil to some extent the Western model of civilization development. On the other hand, the spread of social disintegration in advanced societies is, in all likelihood, unavoidable to some extent: it is a social price which is paid for great advantages in social and economic development. As Durkheim argued (in the case of suicides) "If the spirit of renunciation, the love of progress, the taste of individualization have their place in every kind of society, and cannot exist without becoming generators of suicide at certain points, it is further necessary for them to have this property only in a certain measure, varying with various peoples. It is only justified if it does not pass certain limits $(1989,366)$,"

It seems that in exceeding the "third" world standard, the OECD suicide level is determined not only by greater social disintegration, but also by anomie, which until the present time was a chronic state of postindustrial societies. During the last two hundred years - the period of industrialization, demographic transition, and other turbulence of modern states - the population of these states experienced dramatic changes. Every generation during this period had to adapt to rapidly changing technologies, work habits, cultural and religious traditions, ideology transformations, family erosion, etc. At the end of their lives people left a world, which was very different from what it had been when they were born. It is possible that the speed of changes seemed to be too fast for some of the population, causing permanent, centuries-long anomie, which, consequently, stimulated suicidal behavior in part of the population. Advanced societies, such as the present OECD countries, in the front line of the progress of civilization, had to meet the largest wave of change and, unfortunately, suffer the greatest losses for their societies.

Durkheim, a century ago, treating anomie as "a regular and specific factor in suicide in our modern societies" $(1989,258)$, possibly had hope that anomie would not last long and would diminish together with a growing solidarity in societies. However, it was not until the end of the 20 th century that we have been able to witness signs of stabilization and some decrease in the suicide level in advanced countries, a level which was growing threateningly in the last few 
centuries. According to the available data for the countries of the 19th century presently constituting the OECD, the suicide rate increased from 1866-70 to 1983 (the year with the highest average suicide level for the OECD countries) from 7.8 to 27.0 in Austria, from 6.6 to 23.8 in Belgium, from 6.7 to 8.6 in England (present UK), from 27.7 to 28.6 in Denmark, from 13.5 to 21.8 in France, from 7.6 to 14.6 in Norway, and from 8.5 to 19.0 in Sweden (Durkheim 1989, 50 ; UN).

The latest decrease $10.6 \%$ in the OECD average suicide rate (from 16.0 in 1983 to 14.3 in 1993, see Appendix 1) is based on partially provisional data. It may be determined by accidental fluctuations in suicide dynamics and therefore is not necessarily the correct final rate. However, additional statistics showing that the standard deviation of suicide rates has been diminishing almost regularly from year to year since the beginning of the 1980 s proves that an essential process is taking place in the OECD societies. This process can perhaps be formulated as a unification of the spread of social pathology, at least in the case of suicide. In other words, the closing gap between the highest and lowest suicide rates in individual countries over the latest 14-year period (1980-1993) demonstrates the growing prevalence of suicidal behavior in different OECD societies. If this tendency is not an accidental one, consideration should be given to the existence of a narrowing and a unification in the suicide levels in advanced societies.

In this context the tendency toward a decline in the average suicide rate for OECD societies is all the more impressive, because this decline can be treated as a general (typical) model of social development in social pathology spheres.

This tendency also prompts a hypothesis that a social pathology phenomenon, as a whole, tends to decline, because it should keep some equilibrium with the suicide level. In other words, the peak of the social pathology iceberg - the suicide rate - is taking the same contours for different OECD societies (this is shown by the declining standard deviation), and the less visible part of the iceberg - social pathology of other kinds as a whole - has started melting (this is a logical condition of the decrease in suicides). Of course, this "optimistic" conclusion should be verified by much more exhaustive study than is possible in this short article (and to my limited stock of social knowledge). Nevertheless, it seems that there is enough evidence substantiating the hypothesis of the beginning of a period of declining social pathology in postindustrial societies, e.g., lessening alcohol and tobacco consumption, decreasing drug abuse over the last years in western societies, as well as a growing preference among the population for their lighter forms.

It seems that the impressively reduced rate of traffic casualties also supports the hypothesis of a social pathology decline in advanced societies. At first glance traffic accidents have little in common with the social pathology phenomenon. However, traffic and other accidents can be related to social integration, and, consequently, with social pathology. As Ferge $(1993,12,13)$ argues "Accidents of all kinds (work-related, on the road, etc.) are usually not considered pathologies. They reflect, though, an absence of concern about safety of people, and [...] are signs of an uncaring, badly integrated society."

In such a context exhaustive data of motor vehicle accident casualties for Germany deserve special attention (Figure 3). This society is distinguished by having the highest motorization indicators, a liberal attitude to the speed limit, and "fast" drivers. However, Germany's rate of traffic casualties has more than halved since the 1970s. Similar trends of decreasing traffic accidents are shown by most OECD societies - the average rate of casualties per 100,000 population declined by $44.2 \%$, from 23.3 in $1970-72$ to 13.0 in 1991-95 (unweighted averages for 22 OECD countries, calculated according to UN 1974, 1997 data). The standard deviation of the traffic causalities rate during the same period narrowed by $34.3 \%$, from 7.06 to 4.64 .

These figures demonstrate that despite constantly growing motorization, the advanced societies achieved, in all likelihood, an irreversible turning point in previously negative tendencies of traffic accident development already a few decades ago. This means that OECD societies managed to cope with undesirable consequences related to motorization development and show an ability to keep this process on the decline and under control. 
Figure 3. Development of death rate due to traffic accidents in the Federal Republic of Germany (Germany since 1990-), 1960-1993.

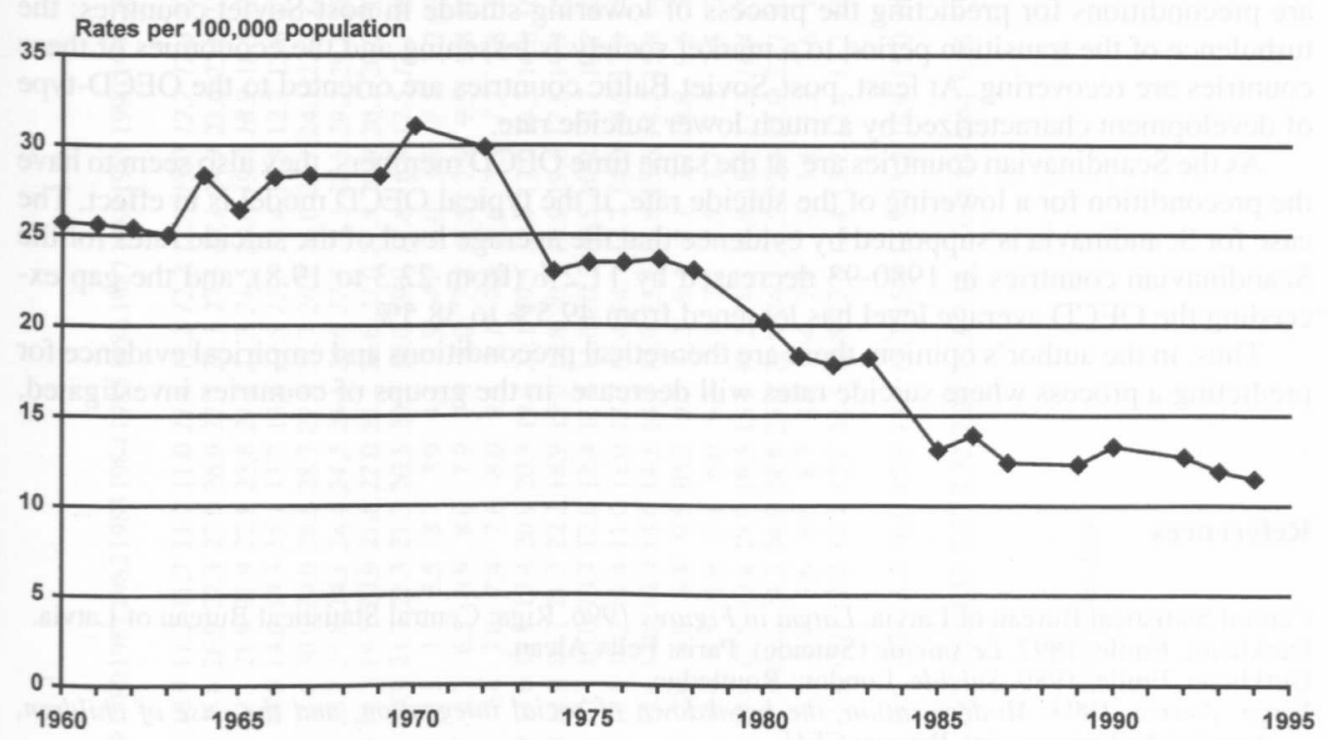

Source: UN 1965-97.

Suicides, of course, cannot be compared to traffic accidents because of the intrinsic complexity of the phenomenon of suicide. Traffic accidents can be relatively easily managed by improvements in technology, driving skills, traffic regulation, road condition development, etc. Suicide, however is a much more complicated psychological, societal, cultural, religious, etc. phenomenon. It seems, however that OECD societies have already achieved a diminishing or at least a precondition for a diminishing in the prevalence of suicide: this is shown by the latest suicide trends, as well as by some other social pathology statistics. If these favorable tendencies are not accidental, the OECD countries may be demonstrating a typical model of suicide development for presently less developed societies of the world.

Such a model is characterized by two stages: first -an increase in suicide during industrialization period of society, and second - a decrease or at least stabilization of suicide in the postindustrial phase of societal development. The first stage can be explained by a long-lasting anomie due to a radical transformation of societies during the last centuries (in the case of the OECD countries) and the incapability of society to adapt to a rapidly changing situation. During the second stage, civilized societies manage to cope with changes or adapt to them. The second stage that advanced OECD countries have possibly achieved, is a fragile one at present, and can be challenged by new radical changes offered by science, technology, and the dissemination of information. However, the experience of advanced OECD societies in recent years seems to confirm the principal possibility of achieving a turning point in the spread of suicide.

\section{Concluding predictions of a decrease in the prevalence of suicide in the post-Soviet Baltic countries and Scandinavian countries on a basis of the OECD model}

In post-Soviet Baltic countries the explosion of suicide in the early 1990 s put them at the top of the suicide rates among countries of the world. In 1993 the average (unweighted) suicide rate for the total population of post-Soviet Latvia, Estonia, Lithuania, and Russia constituted 40.2 and was almost three times the OECD average of 14.3. However, the latest available data 
for the past few years shows some signs of stabilization in the prevalence of suicide: in Latvia suicide rates stabilized and slightly decreased in 1993-95 and in Lithuania they stabilized in 1994-96. (Suicide data was not available for Estonia and Russia after 1994.) It seems that there are preconditions for predicting the process of lowering suicide in post-Soviet countries: the turbulence of the transition period to a market society is lessening and the economies of these countries are recovering. At least, post-Soviet Baltic countries are oriented to the OECD-type of development characterized by a much lower suicide rate.

As the Scandinavian countries are at the same time OECD members, they also seem to have the precondition for a lowering of the suicide rate, if the typical OECD model is in effect. The case for Scandinavia is supported by evidence that the average level of the suicide rates for the Scandinavian countries in $1980-93$ decreased by $11.2 \%$ (from 22.3 to 19.8 ), and the gap exceeding the OECD average level has lessened from $49.5 \%$ to $38.5 \%$.

Thus, in the author's opinion, there are theoretical preconditions and empirical evidence for predicting a process where suicide rates will decrease in the groups of countries investigated.

\section{References}

Central Statistical Bureau of Latvia. Latvia in Figures 1996. Riga: Central Statistical Bureau of Latvia. Durkheim, Emile. 1897. Le suicide (Suicide). Paris: Felix Alcan.

Durkheim, Emile. 1989. Suicide. London: Routledge.

Ferge, Zsuzsa. 1993. Modernization, the breakdown of social integration, and the case of children, unpublished manuscript. Prague: $\mathrm{CEU}$.

Lester, David. 1994. The variation of suicides over time in Scandinavia. Scandinavian Journal of Social Medicine 22(2):159-60.

Okolski, Marek 1991. East-west mortality differentials. In: European population: Vol. 2: Demographic dynamics, European Population Conference, Paris, October 21-25, 1991, edited by Alain Blum and Jean-Louis Rallu, pp. 165-189. Congresses \& Colloquia, No. 9. Montrouge, France: John Libbey Eurotext.

Shkolnikov, Vladimir M., France Meslé, and Jacques Vallin. 1996. Health crisis in Russia. Population: An English Selection, 8:155-190.

Statistikos departamentas prie LR vyriausybes. 1995. Gyventoju mirtingumas nuo savizudybiu (The mortality of population from suicides). Vilnius: Statistikos departamentas prie LR vyriausybes.

Statistikos departamentas prie LR vyriausybes. 1996. Demografijos metrastis 1995 (Demographic Yearbook 1995). Vilnius: Statistikos departamentas prie LR vyriausybes.

Statistikos departamentas prie LR vyriausybes. 1997. Demografijos metrastis 1996 (Demographic Yearbook 1996). Vilnius: Statistikos departamentas prie LR vyriausybes.

UN (United Nations). 1965-97. Demographic Yearbook 1964-95. New York: Statistical Office of the United Nations.

Värnik, Airi, Danuta Wasserman, and Gunnar Eklund. 1994. Suicides in the Baltic Countries, 1968-90. Scandinavian Journal of Social Medicine 22(3):166-9. 


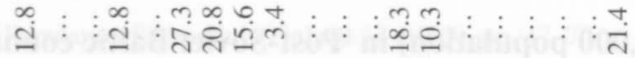

К =m-

=

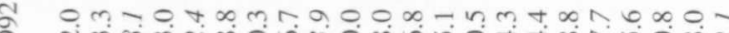

ఏ ปก่ m 0 -

$n$ or

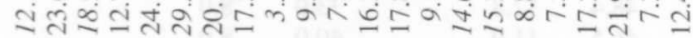

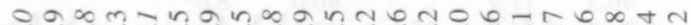

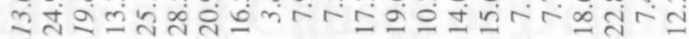

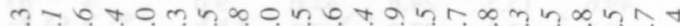

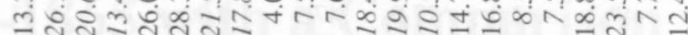

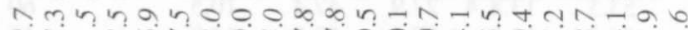

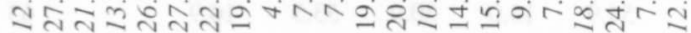

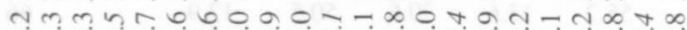

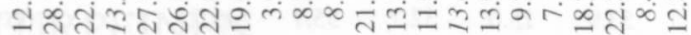

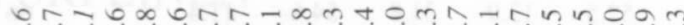

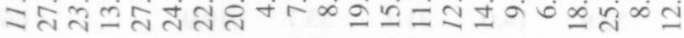
o =

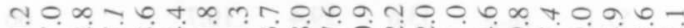
=ลิ่ง

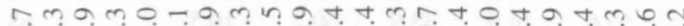

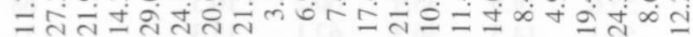
ก =

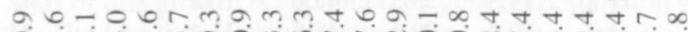
ำกี่

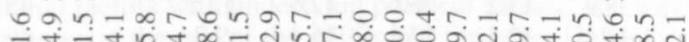
= = $0-\pi m m \infty t r m b m \infty 0 n \pi t a-n \infty 0$

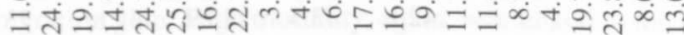

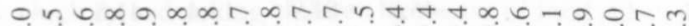

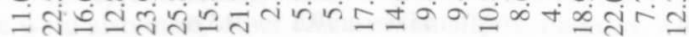
$r=$ -

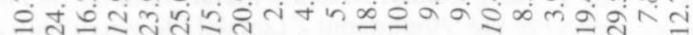

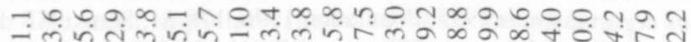

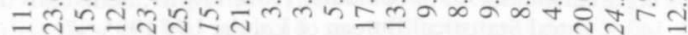

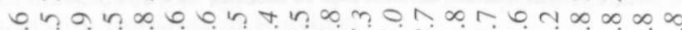

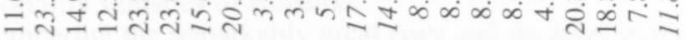
n ปู่

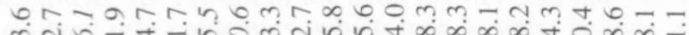
m An m $\tan 0$, n

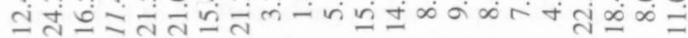
굴 rann m 0 m n 6 n t t ปั่ - to ontymt nt

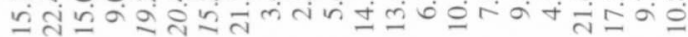
Ұ=0ด

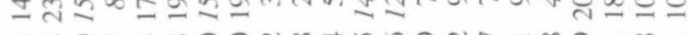

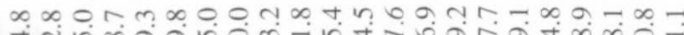
I

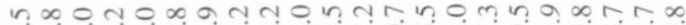

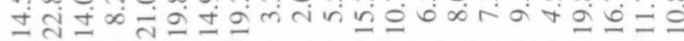
n

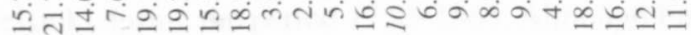
r. mสำ

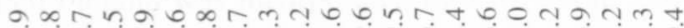

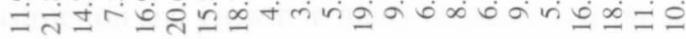

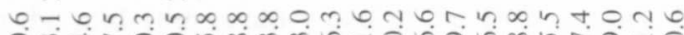

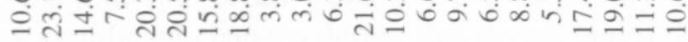

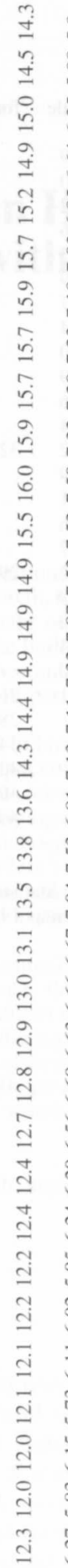

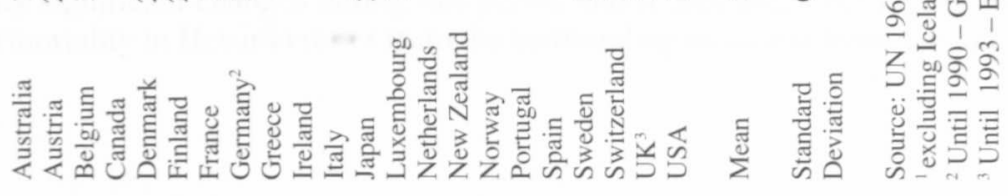


Appendix 2. Suicide rates (per 100,000 population) in Post-Soviet Baltic countries and Russia, 1968-96

\begin{tabular}{|c|c|c|c|c|c|c|c|c|c|c|c|c|}
\hline \multirow[t]{2}{*}{ Year } & \multicolumn{3}{|c|}{ Estonia } & \multicolumn{4}{|c|}{ Latvia } & \multicolumn{3}{|c|}{ Lithuania } & \multicolumn{2}{|c|}{ Russia } \\
\hline & Total & Male & Female & Total & Male & Female & Total & Male & Female & Total & Male & Female \\
\hline 1968 & & 56.2 & 12.9 & & 48.4 & 12.8 & & 33.0 & 8.0 & & & \\
\hline 1969 & & 57.2 & 12.0 & & 46.5 & 11.9 & & 40.0 & 8.0 & & & \\
\hline 1970 & & 52.4 & 14.2 & & 44.8 & 14.0 & 25.1 & 43.5 & 8.8 & & 63 & 12 \\
\hline 1971 & & 55.5 & 13.6 & & 49.6 & 13.5 & 24.8 & 42.6 & 9.0 & & 63 & 12 \\
\hline 1972 & & 57.9 & 12.3 & & 47.3 & 12.0 & 27.0 & 47.3 & 9.0 & & 61 & 12 \\
\hline 1973 & & 50.6 & 13.9 & & 53.5 & 13.8 & 27.9 & 47.4 & 10.5 & & 60 & 12 \\
\hline 1974 & & 54.4 & 14.7 & & 54.9 & 15.0 & 30.9 & 53.3 & 10.9 & & 63 & 13 \\
\hline 1975 & & 65.2 & 13.4 & & 55.2 & 13.6 & 30.6 & 50.5 & 12.9 & & 66 & 13 \\
\hline 1976 & & 56.8 & 15.0 & & 53.9 & 15.0 & 32.2 & 55.7 & 11.2 & & 66 & 13 \\
\hline 1977 & & 59.8 & 13.9 & & 52.5 & 13.9 & 31.8 & 54.6 & 11.4 & & 66 & 13 \\
\hline 1978 & & 56.5 & 14.6 & & 52.6 & 14.0 & 31.1 & 53.7 & 10.9 & & 66 & 13 \\
\hline 1979 & & 56.1 & 15.4 & & 56.0 & 15.2 & 33.8 & 59.9 & 10.6 & & 65 & 13 \\
\hline 1980 & & 55.6 & 15.2 & 32.8 & 53.2 & 14.8 & 35.3 & 63.4 & 10.4 & & 65 & 14 \\
\hline 1981 & & 52.8 & 17.9 & & 57.1 & 18.3 & 33.6 & 59.4 & 10.7 & & 66 & 13 \\
\hline 1982 & & 52.5 & 15.1 & & 54.8 & 16.2 & 33.9 & 58.3 & 12.3 & & 66 & 13 \\
\hline 1983 & & 53.0 & 14.6 & & 55.6 & 14.5 & 33.9 & 60.2 & 10.5 & & 68 & 14 \\
\hline 1984 & & 54.7 & 14.7 & & 56.3 & 14.5 & 36.3 & 62.1 & 13.3 & & 71 & 15 \\
\hline 1985 & & 52.8 & 12.2 & 29.4 & 47.9 & 12.6 & 34.1 & 58.0 & 12.9 & & 59 & 12 \\
\hline 1986 & & 44.0 & 13.9 & & 41.2 & 13.5 & 25.5 & 42.6 & 10.2 & & 42 & 11 \\
\hline 1987 & & 42.4 & 11.2 & & 34.0 & 10.9 & 29.1 & 48.8 & 11.4 & & 44 & 11 \\
\hline 1988 & & 37.4 & 13.4 & & 35.9 & 13.2 & 26.6 & 42.6 & 12.2 & & 45 & 11 \\
\hline 1989 & & 38.9 & 14.0 & & 38.1 & 13.5 & 27.1 & 46.4 & 9.7 & & 49 & 11 \\
\hline 1990 & 27.1 & 41.8 & 14.1 & 26.0 & 43.5 & 10.8 & 26.0 & 44.2 & 9.7 & & 50 & 11 \\
\hline 1991 & & & & 28.5 & & & 30.5 & 52.0 & 11.2 & 26.6 & 50 & 11 \\
\hline 1992 & & & & 34.9 & & & 34.6 & 57.8 & 13.8 & & 59 & 12 \\
\hline 1993 & 38.2 & & & 42.5 & & & 42.1 & 73.5 & 13.9 & 37.8 & 73 & 13 \\
\hline 1994 & 41.0 & & & 40.5 & & & 45.8 & 81.9 & 13.4 & 41.8 & & \\
\hline 1995 & & & & 40.5 & & & 45.6 & 79.1 & 15.6 & & & \\
\hline 1996 & & & & & & & 46.4 & 79.3 & 17.1 & & & \\
\hline
\end{tabular}

Sources: Värnik et al. 1994, 167; Statistikos departamentas 1995; Population 1996, 178-81; Statistikos departamentas 1996, 144; Statistikos departamentas 1997, 142, Central Statistical Bureau of Latvia; UN 1995-97. 